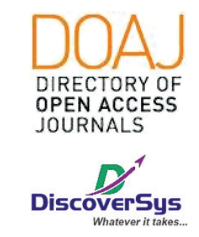

Published by DiscoverSys

\section{Stevens-Johnson Syndrome (SJS)-Toxic Epidermal Necrolysis (TEN) overlap in a 61-year old woman: A case report}

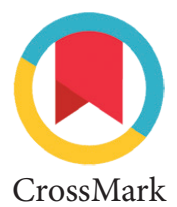

\author{
Luh Gede Melia Puspita Sari, ${ }^{1 *}$ Tjok Dalem Pemayun ${ }^{2}$
}

\title{
ABSTRACT
}

Background: Epidermal necrolysis (EN) is a rare life-threatening reaction. The exact cause of this disease is unknown. However, the drug is one of the main factors as a cause. EN differentiated based on the extent of skin detachment limited to less than $10 \%$ of the body surface area (BSA) in SJS, 10\%-30\% BSA in SJS/TEN overlap, and greater than $30 \%$ of the BSA in TEN. SJS and TEN can occur at various ages, but more often occur at the age of 40 years. Mortality was almost $30 \%$ in SJS/ TEN overlap patients. Management for SJS and TEN is the cessation of drugs that are thought to be the cause and other supportive therapies. Case presentation: A 61-year-old female with SJS-TEN overlap, who presented epidermal detachment, is about $10-30 \%$ with a positive Nikolsky sign. She had a history of taking medication, such as paracetamol, amoxicillin, and buscopan, before lesion appeared. There were multiple lesions widespread, macula hyperpigmentation multiple, erosion from the bullae that has broken, there also erosion covered by black crust, and various erosions covered with black, brown crusts on lip mucosa and also secret on both eyes. The management of this patient was a cessation of suspected drug and supportive therapy. The patient's condition was improved within a few weeks, and no sequelae found.

Conclusion: SJS-TEN overlap is one of the epidermal necrolysis in which skin detachment $10-30 \%$ BSA. The management was a cessation of all suspected drugs, administering high doses of steroids and other supportive therapies.
${ }^{1}$ Medical Doctor, Faculty of Medicine, Universitas Udayana, Denpasar, Bali, Indonesia ${ }^{2}$ Department of Dermatology and Venereology, Wangaya General Hospital, Denpasar, Bali, Indonesia

*Correspondence to: Luh Gede Melia Puspita Sar, Medical Doctor, Faculty of Medicine, Universitas Udayana, Denpasar, Bali, Indonesia

luhgedemelia@yahoo.co.id

Received: 2019-09-14 Accepted: 2020-05-23 Published: 2020-08-01
Keywords: SJS-TEN overlap, allergy, drug, complication.

Cite This Article: Sari, L.G.M.P., Pemayun, T.D. 2020. Stevens-Johnson Syndrome (SJS)-Toxic Epidermal Necrolysis (TEN) overlap in a 61-year old woman: A case report. Intisari Sains Medis 11(2): 606-609. D01: 10.15562/ism.v11i2.618

\section{INTRODUCTION}

Epidermal necrolysis (EN) is a rare life-threatening reaction. EN differentiated based on the extent of skin detachment limited to less than $10 \%$ of the body surface area (BSA) in SJS, 10\%-30\% BSA in SJS/TEN overlap, and greater than $30 \%$ of the BSA in TEN. ${ }^{1}$ The exact cause of this disease is unknown. However, the drug is one of the main factors as a cause. High-risk drugs that cause this disease are allopurinol, antibacterial sulfonamides (cotrimoxazole), carbamazepine, phenobarbital, phenytoin, non-steroidal anti-inflammatory oxicam (meloxicam), lamotrigine, and nevirapine. ${ }^{1,2}$ Onset between drug administration and the reaction is between 4 and 28 days, whereas, in low-risk drugs, it can be longer and usually takes up to 8 weeks. Viral infections and mycoplasma pneumonia infections are also reported as potential causes. ${ }^{2}$ Medication is one of the main risk factors causing SJS/TEN, but it is not certain how drugs can cause epidermal necrosis. T-cells, specifically CD8 + lymphocytes, are thought to play a pivotal role. Besides that, genetic predisposition is also suspected. ${ }^{1,3}$

The incidence of SJS in the world is estimated at 1.2-6 cases/million population/year and TEN 0.4-1.2 cases/million population/year. SJS and TEN can occur at various ages, but more often occur at the age above 40 years. ${ }^{4}$ The incidence of SJS-TEN was known more often between women. ${ }^{5}$ Mortality was almost $10 \%$ in SJS patients, $30 \%$ in SJS/TEN overlap patients, and nearly $50 \%$ in patients with TEN..$^{2,6}$

Before lesions appear on the skin, symptoms of fever, cough, cold, malaise can occur. Symmetrical scattered skin lesions on the face, body and proximal extremities and at least two lesions on the mucosa; oral, genital, or conjunctival. ${ }^{5}$ Lesions in the form of erythema macules, dusky red, irregularly shaped purpura, target lesions can be found then the lesions become necrotic, and bullae arise. Nikolsky's sign is positive in erythema areas. The involvement of internal organs such as lungs, gastrointestinal tract, the kidney can be found. ${ }^{1,5}$ Management for SJS and TEN is the cessation of drugs that are thought to be the cause and other supportive therapies. Further investigations are needed to evaluate the severity of the disease, prognostic, daily care in intensive care. The prognostic scoring system for patients with Epidermal Necrolysis is SCORTEN. ${ }^{7}$ Point 1 include age $>40 \mathrm{yr}$, heart rate $>120$ beats/minute, cancer or hematologic malignancy, body surface area involved $>10 \%$, serum urea level $>10 \mathrm{mM}$, serum bicarbonate level $>20 \mathrm{mM}$, and serum glucose level 
$>14 \mathrm{mM}$. The higher score of SCORTEN, so that the higher of mortality rate. ${ }^{7}$

Based on those mentioned above, this case report aims to evaluate further the SJS case with overlapping TEN in a 61-year-old woman suspected of being caused by the drugs.

\section{CASE PRESENTATION}

A 61-year-old woman, a Balinese, an Indonesian citizen, came to the hospital with her family on July $1^{\text {st }} 2019$, with complaints of appearing red-black spots on almost the entire body. Based on heteroanamnesis, blackish-red spots appear for approximately 4 days before admission to the hospital. Initially, the patient was said to have a fever and abdominal pain. Then the patient gets amoxicillin, paracetamol, and buscopan. After taking the drugs, appears red spots and blisters on the body, lips, and eyelids and also hyperpigmentation. A few days later, the patient becomes weak, and the red spots widespread.

Past medical history, the patient has never experienced the same complaint before. There is no history of diabetes, hypertension, heart disease, or infectious diseases. History of the application of oils or ointments is denied, drinking herbal medicines are also denied. The patient never had a history of drug allergy before as well as a history of allergy in a family member.

Physical examination showed the poor general condition, with GCS $\mathrm{E}_{2} \mathrm{~V}_{2} \mathrm{M}_{6}$. Blood pressure $132 / 80 \mathrm{mmHg}$, axillary temperature $37^{\circ} \mathrm{C}$, pulse $80 \times /$ minute, respiratory rate $20 \times /$ minute. In
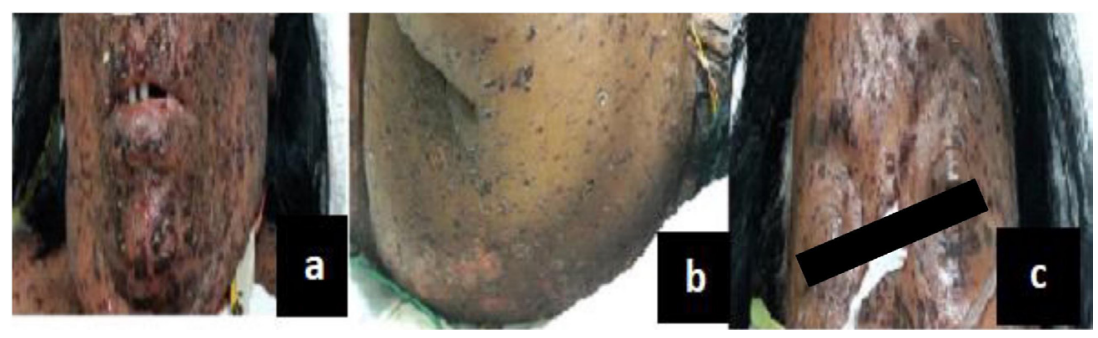

Figure 1 (a) Erosions covered with black crusts on the lips, (b)showed erosion lesions in the back, and (c)Secrets in both eyes

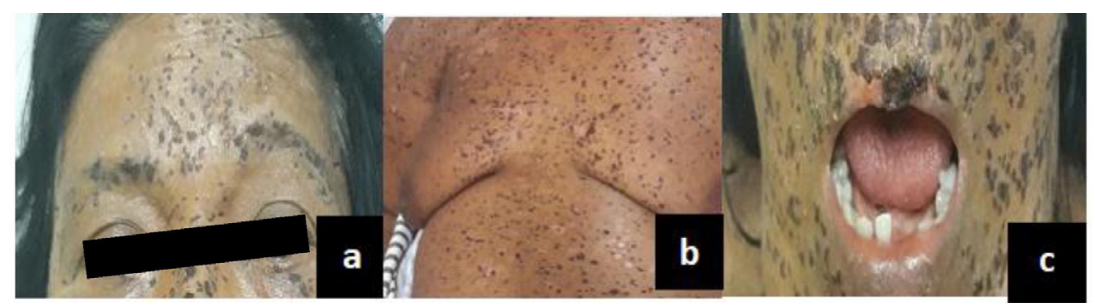

Figure 2 (a)Hypopigmented macular lesions, crusted erosions on the facial region and no secretions on the eyes, (b)Macular lesions hypopigmentation and erosions covered by crust on the chest, (c)Erosion covered by black crusts on the upper lip general status, it is found that the head is normocephali, sclera icteric, there are secretions on both eyes, and erosion on the lips covered with a black crust.

On dermatological status, the face, chest and back, the right and left upper extremities, the right and left lower extremities upper region, there are macula hyperpigmentation multiple widespread. At some locations, there is erosion from the bullae that has broken. There is also erosion covered by black crust. On the mucosa of the lips, there are multiple erosions covered with black, brown crusts. Positive Nikolsky sign. The area of epidermal detachment is about $10-30 \%$.

Supporting examinations carried out on July 1 , 2019, found from blood chemistry examination, obtained SGPT of $492 \mathrm{U} / \mathrm{L}$, SGOT $581 \mathrm{U} / \mathrm{L}$, urea $215 \mathrm{mg} / \mathrm{dl}$, blood creatinine $8.5 \mathrm{mg} / \mathrm{dl}$, glucose when $129 \mathrm{mg} / \mathrm{dl}$. The diagnosis of this patient is SJS-TEN overlap et causa suspected induced by the drug. The patient was treated in cooperation with a specialist of internal disease, anesthesiologist, an ophthalmologist, and pulmonary specialist. Therapy included stopping all suspected drugs, intravenous fluid replacement, intravenous dexamethasone injection $10 \mathrm{mg}$ three times daily, ranitidine $50 \mathrm{mg}$ twice daily intravenously, cetirizine $10 \mathrm{mg}$ once daily, desoximetasone cream $0.25 \%$ and gentamicin cream $2.5 \%$ topical twice a day, triamcinolone cream twice daily for the mucosa lesions. She was treated intensively in the intensive care unit by monitoring fluids according to the anesthesiologist, observing vital signs, expanding skin lesions, skincare, and oral hygiene, she also got eye hygiene beside Cendo Lytters and Cendo Posop 6 times daily on both eyes from an ophthalmologist.

Further observations in the intensive care unit found that both eyes are open and the secretions have been reduced. On dermatological status, the lesion was reduced. Intravenous steroid therapy tapered gradually. Dexamethasone injection decreased to $5 \mathrm{mg}$ three times daily intravenously. She also got levofloxacin $750 \mathrm{mg} / 48$ hours (adjust dose) intravenous from the pulmonary specialist. The following is a patient observation few days after the first admission.

On the subsequent follow-up, there are no new lesions found. Spots on the skin have partially peeled off, and she could eat and drink well. Shortness is denied and no other complaints. On dermatological status in the face, chest and back, the right and left upper extremities, the right and left lower extremities upper region, there are erosion covered by black crusts widespread. In some parts, there are macular hypopigmentation and macular hyperpigmentation. On the lip mucosa, there are multiple erosions covered by black crusts. Dexamethasone 
therapy was reduced to $1 / 2$ ampoule once daily. A few days later, the treatment was changed to methylprednisolone $4 \mathrm{mg}$ three times daily, ranitidine $150 \mathrm{mg}$ twice daily orally. The patient was reviewed within two weeks. The lesion had healed significantly in oral mucosa and skin.

\section{DISCUSSION}

Epidermal Necrolysis is acute life-threatening mucocutaneous reactions. Drugs most often cause the disease with onset between the reaction and the administration of drugs from most drugs is between 4 to 28 days, whereas in low-risk drugs can be longer and usually a maximum of up to 8 weeks. This case is more common in women and more often at the age of $>40$ years. ${ }^{2,5}$

The patient is a 61year old woman. Based on heteroanamnesis, the patient has red spots about 4 days before admission. Previously, the patient took drugs because of fever and stomachache; then red spots appear a day after taking the drugs. The medicines that have a high risk of causing this disease are allopurinol, sulfonamide carbamazepine, phenobarbital, phenytoin, non-steroidal anti-inflammatory oxicam, lamotrigine, and nevirapine. ${ }^{1,2}$ But in this case, the patient took paracetamol, amoxicillin, buscopan. There were cases reported by Biswal, et. all where a 12-year-old child had a severe case of SJS/TEN after administration of $500 \mathrm{mg}$ of paracetamol at 8-hour intervals to treat fever. ${ }^{8}$ Similarly, the case reported by Rajput, et al. was a 14-year-old boy who had SJS after taking paracetamol. ${ }^{9}$ Patients also take amoxicillin. Case report Krystyna, et al. also presents a 54-year-old woman experiencing SJS/TEN overlap after consuming amoxicillin. ${ }^{10}$ Hypersensitivity reactions to hyoscine butylbromide content in buscopan may be mediated by IgE. ${ }^{11}$

Skin eruption in SJS/TEN is symmetrically spread over the face, body, proximal extremities in the form of erythema macules, dusky red, irregular shape purpura, can be found target lesions then lesions become necrotic, bullae arise. ${ }^{3}$ Nikolsky's sign is positive in erythema areas. Involvement of internal organs such as the lung, gastrointestinal tract, kidneys can be found. ${ }^{1,5}$ In this case lesions were found in the face, chest and back, the right and left upper extremities, the right and left lower extremities upper region there are multiple lesion widespread, in some locations there is erosion originating from bullae that have broken, there are also erosions covered by black crusts. On the lip mucosa, there are multiple erosions covered by black, brown crusts. Positive Nikolsky sign. The area of epidermal detachment is about $10-30 \%$. SJS-TEN overlap shows epidermal damage between $10-30 \% .{ }^{1,2}$
There are no laboratory tests to support the diagnosis. Additional examination performed on patients with SJS/TEN is important to evaluate the severity of the disease, prognosis, daily care in intensive care. In this case, supporting examinations such as routine blood tests, liver and kidney function, blood sugar, electrolytes, urine, x-ray thorax-prognosis based on SCORTEN score. The prognosis of this patient cannot be evaluated because bicarbonate is not tested.

The management, in this case, is the cessation of suspected drugs and other treatments that are supportive. Therapy also aims to prevent long-term sequelae, such as mucous membrane stricture and symblepharon, which significantly causes morbidity in SJS and TEN patients. Supportive treatment can be treated in a particular room, such as a burn unit or intensive care unit, fluid replacement with an electrolyte solution, and albumin. Treatment of the patient's skin and mucosa is also carried out. In addition, it is also necessary to consider nutritional needs through the nasogastric tube, as well as monitoring for infections and to provide empirical antibiotic therapy if needed. The immunological and cytotoxic systems play an important role in the mechanism of this disease, although the pathophysiology is still unknown. Immunosuppressant and anti-inflammatory therapy is widely used to suppress the progression of diseases, such as corticosteroids, intravenous immunoglobulin, cyclosporine a, and anti-TNF., ${ }^{1,5}$ The use of it still controversial. Some reports show steroid therapy can reduce mortality, but other studies have not demonstrated the risk of mortality. ${ }^{12-14}$

In this case, the patient was in intensive care unit and treated in cooperation with a specialist of internal disease, anesthesiologist, an ophthalmologist, and pulmonary specialist. The patient also got nutrition via a nasogastric tube. The management is stopping all suspected drugs, such as paracetamol, amoxicillin, or buscopan. Patients also get intravenous corticosteroid therapy, initially dexamethasone $10 \mathrm{mg}$ three times daily, then reduce gradually after the patient showed improvement. Topical steroids are given in combination with antibiotics because there is erosion in several parts of the patient's body; the lip mucosa is also given topical steroids. Dexamethasone is a potent glucocorticoid that can inhibit epidermal apoptosis by suppressing various cytokines such as TNF- $\alpha$ and Interferon Gamma which has been used from the previous reports. ${ }^{15,16}$

\section{CONCLUSION}

A case of SJS-TEN overlap has been reported in a 61-year-old woman suspected of being caused by 
drugs. The diagnosis in this patient is made clinically based on history taking and physical examination. Investigations are carried out to evaluate the severity of the disease, prognosis, daily care in intensive care. The management was a cessation of all suspected drugs. Besides, administering high doses of steroids and other supportive therapies. In a few days, the patient's condition improved and there were no sequelae found.

\section{CONFLICT OF INTEREST}

The author declares that there is no conflict of interest.

\section{FUNDING}

The authors are responsible for the funding of the study.

\section{AUTHOR CONTRIBUTION}

All of the authors are contributed to the study.

\section{REFERENCES}

1. Dodiuk-Gad RP, Chung WH, Valeyrie-Allanore L, Shear NH. Stevens-Johnson Syndrome and Toxic Epidermal Necrolysis: An Update. Am J Clin Dermatol. 2015;16(6):475-493.

2. Mockenhaupt M. The current understanding of StevensJohnson syndrome and toxic epidermal necrolysis. Expert Rev Clin Immunol. 2011;7(6):803-815.

3. Harr T, French LE. Toxic epidermal necrolysis and StevensJohnson syndrome. Orphanet J Rare Dis. 2010;5:39.

4. Mochtar M, Negara WP, Murasmita A. Angka Kejadian Sindrom Stevens-Johnson dan Nekrolisis Epidermal Toksik di RS Dr. Moewardi Surakarta Periode Agustus 2011-Agustus 2013. MDVI. 2015;42(2):65-69.

5. Yang MS, Lee JY, Kim J, Kim GW, Kim BK, Kim JY, et al. Incidence of Stevens-Johnson Syndrome and Toxic Epidermal Necrolysis: A Nationwide Population-Based Study Using National Health Insurance Database in Korea. PLoS One. 2016;11(11):e0165933.
6. Diphoorn J, Cazzaniga S, Gamba C, Schroeder J, Citterio A, Rivolta AL, et al. Incidence, causative factors and mortality rates of Stevens-Johnson syndrome (SJS) and toxic epidermal necrolysis (TEN) in northern Italy: data from the REACT registry. Pharmacoepidemiol Drug Saf. 2016;25(2):196-203.

7. Seecof OM, Liantonio J. Prognostication Using SCORTEN Severity of Illness Score in Patients With Stevens Johnson Syndrome and Toxic Epidermal Necrolysis. J Pain Symptom Manage. 2019;57(1):e8-e9.

8. Biswal S, Sahoo SS. Paracetamol induced Stevens-Johnson syndrome--toxic epidermal necrolysis overlap syndrome. Int J Dermatol. 2014;53(8):1042-1044.

9. Rajput R, Sagari S, Durgavanshi A, Kanwar A. Paracetamol induced Steven-Johnson syndrome: A rare case report. Contemp Clin Dent. 2015;6(Suppl 1):S278-S281.

10. Romańska-Gocka K, Gocki J, Placek W, Zegarska B, Krause P. Stevens Johnson syndrome after carbamazepine and SJS/TEN overlap syndrome after amoxicillin: case reports and a review. Arch Med Sci. 2010;6(1):130-134.

11. Diaz MY, Torrijos EG, Lozano LM, Ortega AME, Rodriguez RG, Lopez $\mathrm{MCH}$, et al. Immunoglobulin E-Mediated Severe Allergy to Hyoscine Butylbromide. J Investig Allergol Clin Immunol. 2018;28(4):255-254.

12. Liu W, Nie X, Zhang L. A retrospective analysis of StevensJohnson syndrome/toxic epidermal necrolysis treated with corticosteroids. Int J Dermatol. 2016;55(12):1408-1413.

13. Law EH, Leung M. Corticosteroids in Stevens-Johnson Syndrome/toxic epidermal necrolysis: current evidence and implications for future research. Ann Pharmacother. 2015;49(3):335-342.

14. Morita K, Matsui H, Michihata N, Fushimi K, Yasunaga H. Association of Early Systemic Corticosteroid Therapy with Mortality in Patients with Stevens-Johnson Syndrome or Toxic Epidermal Necrolysis: A Retrospective Cohort Study Using a Nationwide Claims Database. Am J Clin Dermatol. 2019;20(4):579-592.

15. Kardaun SH, Jonkman MF. Dexamethasone pulse therapy for Stevens-Johnson syndrome/toxic epidermal necrolysis. Acta Derm Venereol. 2007;87(2):144-148.

16. Sudarsa P, Puspawati N, Purnama N, Sanjaya I, Hamid A. Toxic Epidermal Necrolysis (TEN) in an elderly with comorbidities: a case report. Bali Medical Journal. 2020;9(1):323-326.

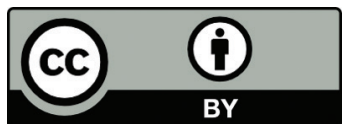

This work is licensed under a Creative Commons Attribution 